\title{
Journal of Intellectual Disabilities
}

http://jid.sagepub.com

Using blended and guided technologies in a university course for scientist-practitioners: Teaching Applied Behaviour Analysis to autism professionals

Lise Roll-Pettersson and Shahla Ala'l-Rosales

Journal of Intellectual Disabilities 2009; 13; 113

DOI: $10.1177 / 1744629509340179$

The online version of this article can be found at:

http://jid.sagepub.com/cgi/content/abstract/13/2/113

\section{Published by:}

(-)SAGE

http://www.sagepublications.com

Additional services and information for Journal of Intellectual Disabilities can be found at:

Email Alerts: http://jid.sagepub.com/cgi/alerts

Subscriptions: http://jid.sagepub.com/subscriptions

Reprints: http://www.sagepub.com/journalsReprints.nav

Permissions: http://www.sagepub.co.uk/journalsPermissions.nav

Citations http:/jid.sagepub.com/cgi/content/refs/13/2/113 


\title{
Using blended and guided technologies in a university course for scientist- practitioners
}

\author{
Teaching Applied Behaviour Analysis to autism \\ professionals
}

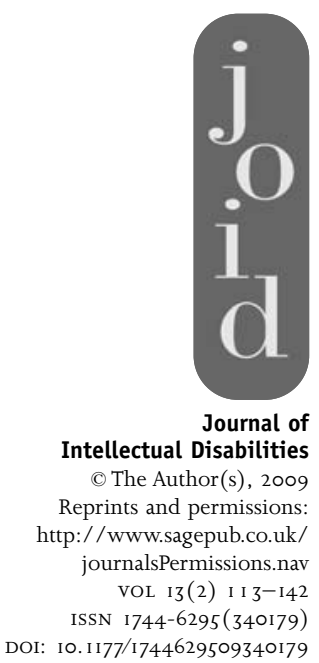

S H A H L A A L A ’ I - R O S A L E S University of North Texas, USA

\begin{abstract}
Although the incidence of autism spectrum disorders is increasing worldwide, there is a shortage of professionals trained to provide effective interventions. The article describes an advanced university course in Applied Behaviour Analysis (ABA) and autism tailored to meet the needs of Swedish professionals from multiple disciplines. The course implemented both blended-learning technologies (web, telecommunication, and in vivo) and guideddesign (problem-solving) exercises to promote the scientistpractitioner model. Overall, students advanced their skills related to identifying extant scientific literature, choosing appropriate singlesubject design evaluation methods, and critically analysing the effects of attempted interventions. Students rated the course as having high social validity and predicted the course content would positively affect their professional practice. The relevance of the course and future directions are discussed in the context of meeting the global need for effective autism intervention professionals.
\end{abstract}

Keywords Applied Behaviour Analysis; autism; blended learning; guided design; scientist-practitioner

The incidence of autism appears to be increasing worldwide (Centers for Disease Control, 2007; Johnson and Myers, 2007), and professionals are struggling to address the accelerating demand for effective intervention and management of the disorder (McGee and Morrier, 2005; Myers and Johnson, 2007; Volkmar et al., 2005). Universities are typically responsible for the preparation and education of autism intervention professionals 
(National Research Council, 200I; Scheurmann et al., 2003; Shook et al., 2002). The purpose of this article is to provide a description of the methods and outcomes of an autism course designed for advanced professionals in Sweden. While the model focused on professionals in Sweden, the approach can be adapted in locations with limited access to training resources in autism.

\section{Introduction}

It is well established that early intervention plays a critical role in aiding the favourable development of social, cognitive and language skills in young children with autism (e.g. Fenske et al., 1985; Howard et al., 2005; Koegel et al., 1999; Lovaas, 1987; Wolf et al., 1964) and in remediating the symptoms of autism and increasing functional skill development in older individuals (Myers and Johnson, 2007). Most of these interventions are based on Applied Behaviour Analysis (ABA). ABA has been described by Anderson and Romanczyk (1999) as a 'bottom-up' approach in which principles and procedures that have demonstrated efficacies through previous objective evaluation (published in peer-reviewed journals) are assembled into new models that are then again offered up for scientific evaluation. In this way, intervention models are continually developing and improving based on cumulative knowledge within the field. This knowledge base is found in regard to both increasing skills in specific domains (e.g. Goldstein, 2002; McConnell, 2002; Stahmer et al., 2003) and decreasing harmful behaviour (Machalicek et al., 2007). Swedish habilitation employers (Bohlin et al., 2004) recommend early and intensive behavioural interventions (EIBIs) for young children with autism. Interventions based on Applied Behaviour Analysis are spreading rapidly in Sweden (Granat, Assistant Director of Habililitation for Children, Youth, and Adults in the County Council of Uppsala, personal communication, 22 March 2007) and are prevalent in varying degrees in habilitation centres throughout the country (Folkö, 2005).

Paradoxically, current academic training in Sweden does not correspond with the increasing demand for ABA programmes. Although international competency recommendations for professionals serving children with autism exist (Grey et al., 2005; Scheuermann et al., 2003; Shook et al., 2002), at present there are no official guidelines regarding accepted content and skills standards for professionals serving children with autism. According to Scheuermann et al. (2003), the array of learning difficulties constituting autism underscores the importance of advanced professional training. Of particular importance is understanding of and familiarity with evidence-based interventions and being able to distinguish between 
effective treatment and fad treatment. Without such training, professionals may create situations in which instruction either is ineffective or has a negative impact on the child (Bibby et al., 200I; Howard et al., 2005). In order to promote effective interventions, there is a critical need to train advanced professionals. This would entail the development of advanced courses and degrees that conform to scientific intervention standards as well as to the ecological and cultural contingencies of a given community.

Four groups of literature informed the design of the advanced training course for the students in Sweden. First, we examined the literature on clinical approaches to practice among the professions actively involved in supporting children with autism; second, we reviewed accounts of successful pedagogy precedents and postgraduate training programme pedagogy; third, we considered specific discipline content recommendations regarding autism intervention competencies; and, finally, we investigated technological advances in university instruction that would aid in course delivery. Each of these information sources will be addressed, and then the course and its outcomes will be described.

\section{Clinical approaches}

Since the middle of the twentieth century, there has been a developing trend emphasizing the need for practitioners in the helping professions to ground clinical and educational practice in science in order to reduce the research-practice gap (Gambrill, 1999). As early as 1949, doctoral training standards for 'scientist-practitioners' were suggested in an attempt to integrate psychological research and practice (Baker and Benjamin, 2000; Horn et al., 2007). As the concept of the scientist-practitioner developed, an 'attitude of science' was promoted that encouraged 'skepticism, curiosity and inquiry', combined with the art of clinical practice (Striker, 2000, p. 254). Simultaneously, a new discipline, Applied Behaviour Analysis (ABA), emerged from psychology; in essence, $A B A$ mandated the integration of practice and research.

ABA was grounded in a scientific approach to socially important problems (Baer et al., 1968; Goldiamond et al., 1965). It was characterized by interventions that employed direct measures, single-subject research designs, and consultation with extant research (Lutzker and Campbell, 1994). The trend continued and developed further with the introduction of evidence-based practice to the medical (Sackett et al., 1996) and education professions (Horner et al., 2005). Evidence-based practice requires that the clinician identify the clinical issue, consult and appraise extant relevant research literature, apply the best available evidence, and evaluate the findings recursively (Geddes and Harrison, 1997). The trend toward the integration of science and practice has become a pervasive theme across multiple disciplines and is considered the gold standard to 
which the helping professions are held (Dunst et al., 2002), and extends to the professions serving children with autism (Ozonoff et al., 2005).

\section{Successful pedagogy precedents}

Research findings suggest that guided feedback, practice and training situations that closely resemble the final conditions of performance are effective in teaching adult learners (Alai-Rosales et al., 2003; Bernstein, 1982; Demchack, 1987; Harchik et al., 1992; Shook et al., 2002; Trivette, 2005). Alai-Rosales et al. (2003) conducted a literature review over studies which focused on the effects of teaching either professionals and/or paraprofessionals who would be responsible for children and adults with autism and other developmental disabilities. In general, the studies were divided into two categories: those that concentrated on directly teaching a set of intervention techniques, and those that focused on techniques and problem solving. Studies in the first category included teaching instructional arrangements, modelling, prompting, and reinforcement techniques. The second category focused on similar techniques but also included instruction geared toward generative, problem-solving behaviour on the part of the professional/paraprofessional in training. For example, Peck et al. (1989) provided teachers with videos of their teaching so they could evaluate themselves and more closely align their teaching to a child's educational goals. This procedure increased the child's progress. Each of the studies reviewed took place in the context of a specific training programme that was outside, or in addition to, university course work.

Two studies specifically addressed training the interventionist within a university frame. In one study, Alai-Rosales et al. (2003) describe a teacher training programme designed by Donald Baer and colleagues at the University of Kansas (KU). In this two-year training programme, Baer and colleagues maintained that in addition to formal courses in behaviour analysis, interventionists-in-training should quickly become involved in multiple research and experimental teaching projects. The students selected ongoing problems that integrated classroom knowledge and analytical problem-solving skills. Many of the problems concerned increasing the effectiveness of teacher training programmes. The authors present one example of this process: a doctoral student who worked with a master's student to systematically teach and evaluate the effects of training three student teachers to instruct children. The data from the student teachers and the three children (who were between 5 years 8 months and 6 years 5 months) were presented. Findings revealed that the training resulted in increases of favourable teaching techniques (clearer instructions, praise, and error corrections) and decreases in child errors on academic tasks (for example, name identification, handwriting, and mathematics). In a second 
study, conducted at Trinity College Dublin, Grey et al. (2005) worked intensively (9o class hours for I3 days, over a 7 month period) with special education teachers whom they taught to conduct functional assessments and design behaviour-change programmes for children with autism. The training programme, which was designed based on the recommendations of the Behaviour Analysis Certification Board, resulted in the reduction of problematic student behaviour and/or an increase in student skills among I I children diagnosed with an autistic disorder, who were between 2 years Io months and I5 years, with a mean age of 8 years 2 months.

Both the Grey et al. and the Alai-Rosales et al. studies incorporated a pedagogy programme for adult learners that is gaining recognition; namely, 'guided design'. The approach was developed in the field of engineering, and its effectiveness is documented in both engineering and nursing (Trivette, 2005). Guided design is an instructional method that includes a sequential process for problem solving, uses small group teaching technology, provides feedback on students' work and focuses on realistic problems' (2005, p. I). A practice-based research synthesis of 35 studies in higher education that utilized or compared guided design to other methods indicated that students in guided-design groups learned to apply course content to realistic problems and gained increased confidence in their professional skills (Trivette, 2005).

\section{Discipline content recommendations}

The two primary guides of relevance for professionals utilizing the principles and procedures of ABA and working with children with autism are the Behaviour Analysis Certification Board Task List ${ }^{\text {TM}}$, which outlines the basic skills required of a behaviour analyst (Shook et al., 2004), and the recommendations described by the Association of Behavior Analysis Autism Special Interest Group. The latter prescribes additional requirements for behaviour analysts practising autism interventions. Both sources outline a comprehensive series of skills, ranging from proficiency in assessment and teaching procedures to data analysis and evaluation techniques, to ethical conduct. These formed the core of the present course content. Following recommendations that it is imperative that university training of autism professionals focuses on teaching empirically grounded practices (Scheurmann et al., 2003; Shook et al., 2002; National Research Council, 200I), a review of current intervention research was also included in the course content.

\section{Technological advances in university instruction}

Finally, we investigated technological advances that might increase the effectiveness of the course. Distance education is an area that is growing 
rapidly in higher education and offers new potential for students and groups when the necessary information is not readily accessible. Blended or hybrid courses craft mixtures of traditional face-to-face instruction with online (web, CD, telecommunication) content. Allen et al. (2007) classified a course as blended if 30-79 percent of content was online. According to Bonk et al. (2004), blended learning utilizes virtual technology as a way to endorse rich interactive learning experiences, and offers potential for synchronizing students and instructors with expertise spread throughout the world. It is thereby possible to design courses to meet the specific needs of groups of learners. In a survey distributed to educators and corporate respondents, the findings revealed that the majority predicted that handson learning (i.e. linking work with learning) would become the dominant feature of blended-learning techniques, and that it has the potential to foster cross-cultural understanding and increase global collaboration (Bonk et al., 2004). Allen et al. (2007) collected data over a 3 year period from 2300 persons affiliated with over rooo colleges and universities in the United States concerning their perceptions and use of fully online contrablended course offerings. The overall results revealed that online courses have increased, but that blended learning appears to be more of 'a discrete option which institutions choose on its own merits'. Given the shortages of advanced intervention expertise in autism, blended instruction appeared to be an ideal means of increasing the training resources available to students of autism intervention. The purpose of this article is to describe the methods and outcomes of an advanced course in ABA autism intervention that used guided design and blended-learning technologies. The effectiveness of the course was evaluated through analysis of the students' guided-design experimental teaching project and through a questionnaire regarding the social validity of the course from the students' perspectives.

\section{Method}

\section{Participants}

The participants consisted of two university instructors, 18 university students, I3 children with autism whose ages ranged from 3 years and 3 months to 15 years, with whom the students conducted their experimental teaching projects, and technical support personnel.

Instructor on-site The on-site instructor (first author) had a bachelor degree in pre-school and special education, a $\mathrm{PhD}$ in education and over 20 years of teaching experience. She had limited exposure to single-subject design and scientist-practitioner training methodologies. Her training in 
applied behaviour analysis was through post-doctoral distance education courses. The on-site instructor co-designed and coordinated the course, and graded assignments, planned meetings and provided feedback to the students. She was also responsible for correspondence with the students using the Moodle web-based communication system and was the liaison between the distance instructor and students.

Instructor-at-distance The instructor-at-distance (second author) had a bachelor degree in Child and Family Studies, a master of arts in Human Development, and a PhD in Developmental and Child Psychology. Her postgraduate training was all within a scientist-practitioner model. She had I5 years experience of teaching university master-level courses in behaviour analysis and more than 25 years clinical experience in autism.

The instructor-at-distance co-designed the course, implemented guided instruction programs, taped topic CDs, and consulted with students via monthly telecom conferences. In addition, she supported students in generating, developing and implementing their experimental teaching projects.

Students At the onset of the course, 23 students from several disciplinary backgrounds participated in the course: one middle school teacher, one occupational therapist, one preschool teacher, one psychologist, i6 special educators, and three speech and language pathologists. Eighteen students were able to complete the course. Five students withdrew due to work, health, or other personal issues. All had worked with a least one child with autism and had had at least three years' experience working with children with autism in a variety of settings: special education programmes, preschools, or as consultants working within the municipality or a habilitation centre. All the students previously participated in a traditional and web-facilitated course in Applied Behaviour Analysis, in which the first author was the lead instructor. The content of the course was based on minimal educational criteria outlined by the Behaviour Analyst Certification Board ${ }^{\mathrm{TM}}$ in order to practise as an associate behaviour analyst.

Support personnel Technical support was provided by the Centre for Media Production at the Stockholm Institute of Education and at the Centre for Distributed Learning at the University of North Texas. This included telecommunication scheduling and administration, web establishment and support, and sharing information regarding instructional resources.

\section{Procedure}

The course described in this article is a collaborative endeavour between the University of North Texas and the Stockholm Institute of Education. 
Together, through e-mail and phone conversation, the authors clarified expectations and established agreement regarding course goals and outcomes. The intention was to design a course based on a scientistpractitioner approach, combining international expertise with the ecocultural needs of the specific students attending the course (e.g. Swedish higher education course structure and credit system, service delivery methods and mechanisms, etc.) Students who completed the 15 ECTS credit course with passing grades and also met $\mathrm{BACB}^{\mathrm{TM}}$ minimum requirements regarding supervision and degree level would be qualified to take the BACB exam and become board-certified behaviour analysts.

\section{Course content and structure}

An outline of the course content, blended-learning mixtures and activities is included in Table I. Utilizing the blended-learning approach, students met the instructor on-site at the Stockholm Institute of Education on 17 full days over a 9 month period (September-May). Generally, the morning sessions started with an in-class group quiz on selected readings. This was followed by class discussions, a lecture, or group presentations on guided projects. Afternoon sessions consisted of project presentations or telecom conferences (instructor-at-distance or CD lectures by second author or visiting scholars). Consistent with the guided-design approach to student engagement (see Trivette, 2005), the students were involved in 'integration' projects that were sequentially and cumulatively organized: all activities involved teams and small groups consisting of two to four students. The instructors provided feedback during several phases of the projects, and all projects were based on situations encountered by behaviour analysts working in the field of autism. A complete description of all projects and the guided-design methods is given in Table 2. The instructor-at-distance came to Sweden for two of the final class days of the course. The first day was devoted to reviewing, integrating and discussing total course content through case study scenario exercises. The final day of the course was devoted to a symposium presentation by the students of the results of the experimental teaching projects.

\section{Course evaluation methods}

For the purpose of this article, two types of course evaluation were offered: performance and outcomes of the experimental teaching project, and the students' evaluations of the course.

Experimental teaching project At completion of the course, students presented a description of their experimental teaching projects in which they were instructed to teach a pupil with autism a new skill of social 
Table 1 Overview of course content and blended mixtures

Topic Brief description

Delivery method and activities

\section{Autism and Applied Behaviour Analysis}

Readings: quiz; face-to-face lecture; written exercise and discussion

\section{Family support and participation}

Readings: quiz; CD lecture; roleplay exercise and discussion

\section{Professionalism and ethics}

Readings: quiz; telecom lecture; written exercise and discussion

\section{Ecological systems}

Readings: quiz; CD lecture; written exercise and discussion

\section{Accountability}

Readings: quiz; telecom lecture; practice exercise; visiting professor lecture; experiment analysis and discussion

\section{Evidence-based treatment options}

Readings: quiz; telecom lecture; position paper analysis and discussion; telecom presentation and feedback about experimental teaching project

\section{Teaching procedures}

Readings: quiz; visiting professor lecture; practice exercise; experiment analysis and discussion

\section{Curricular issues}

Readings: quiz; telecom lecture; face-toface lecture and discussion; small group presentation and discussion
Scientific views of human behaviour; overview of dimensions of $A B A$; applications of $A B A$; history of $A B A$ in the treatment of autism

Challenges faced by families; training and support literature; components of effective training programmes; effective interaction techniques

Knowledge and competencies required of behaviour analysts working in autism; professional behaviour; key ethical guidelines in autism treatment settings; ethical considerations when designing interventions

Overview of behavioural systems theory; contingencies between training, maintenance and generalization in autism organizations; common elements of PBS applications

Principles of evidence-based practice; recording systems; single-subject design; data collection systems; precision teaching methods and techniques

Rules of evidence in evaluating research in autism treatment; domain specific (communication, social, activity, selfmanagement) research outcomes and procedures; evidence-based intervention procedures and formats

Elements of effective teaching; lesson formats/teaching programmes; instructional presentations and rules

Scope and sequence of effective intervention programmes; theoretical perspectives on curriculum progression; review and analysis of behavioural curricular approaches 
JOURNAL OF INTELLECTUAL Disabilities i 3 ( 2)

Table 2 Guided design projects

Project Goals

Method

\section{$A B A$ document}

Small group development with feedback and revisions

\section{Ethics document}

Small group development with feedback and revisions

\section{Curricular analysis}

Small group development with whole group presentations and discussion

\section{Professional interaction skills}

Group roleplays with feedback and discussion

\section{Case study scenarios}

Small group discussion with instructor guidance and discussion; whole group summary and discussion

\section{Experimental teaching project}

Small group development and implementation; three telecom conferences; e-mail discussions; phone discussions; faceto face discussions; whole group presentations and discussion

\section{Mock exam}

Individual responses; small group discussion and feedback
Describe with technical accuracy and in lay language the dimensions of $A B A$ and the benefits of behavioural approaches to the treatment of autism

Identify key BACB ethical guidelines; articulate to staff and families guidelines as they apply to current employment setting of the student setting; describe the issues and considerations involved when balancing personal liberties and habilitation of clients in that setting

Locate curricula for students with autism; identify scope and sequence; assess extent of empirical evidence; analyse and evaluate the shortcomings and advantages of the curricula

Practise critical components of professional and child centred interactions with parents, peers and supervisors

Integrate and apply course content areas to a range of real-life clinical situations that encompass lifespan, severity, systems, and evidence considerations

Practise evidence-based clinical method within domains of communication, social/play, independence and conceptual/problem solving; address ethical, professional, family participation issues; demonstrate a functional relationship between intervention and the child's favourable outcome; place this outcome in the context of the current state of science and offer a discussion of the possible explanations for the behaviour change

Practise format of BACB exam; integrate knowledge areas and experiences with all course content areas 
importance, using the evidence-based scientist-practitioner method. The instructions for the experimental teaching projects were as follows. In small groups of two to four persons, select a specific behaviour or skill that is important to a person with autism with whom you work, and which you wish to increase; conduct a literature search of how other researchers have taught this behaviour or skill; and review the research designs that were implemented. Students were instructed to find at least three published peer-review articles for this assignment. They were also instructed to evaluate the project by considering factors such as social validity and ethics, as well as to analyse the results and consider how their study might impact research within the field, including changes that might evolve from them. The project was introduced to students at the beginning of the course and through telecom conferences. They received advice monthly, beginning in January, from the instructor-at-distance via telecom conferences.

The projects were presented both in writing and orally. A description of each teaching project, including reference to evidence base, number of participants, recording technique, and evaluation method is included in Table 3.

Questionnaire A modified version of the Teacher Evaluation Instrument developed by Grey et al. (2005) was used to collect information regarding students' perceptions of the social validity of the course content. The Grey et al. questionnaire consisted of is items which seemed appropriate to the content of the course, and provided a method to capture students' perceptions of the pros and cons of the learning techniques that the course utilized. Seven of the items were reworded or modified to meet the needs of the present study, and six items were identical to items used in the Grey et al. study. Student responses in both surveys were made in a five-degree Likert format in which $\mathrm{I}=$ less than expected and a $5=$ greater than expected. Students were also requested to list the three most useful aspects of the course and three features of the course which they thought could be improved. The survey was administered at the final meeting of the class. Student satisfaction was also assessed in free-text format: the students were instructed to jot down what they learnt and to note areas in which they would have liked further guidance and instruction.

\section{Results}

\section{Experimental teaching projects}

Table 4 provides a summary of the results and main lessons learned (and articulated by the students) in each of the in projects. Overall, with varying 


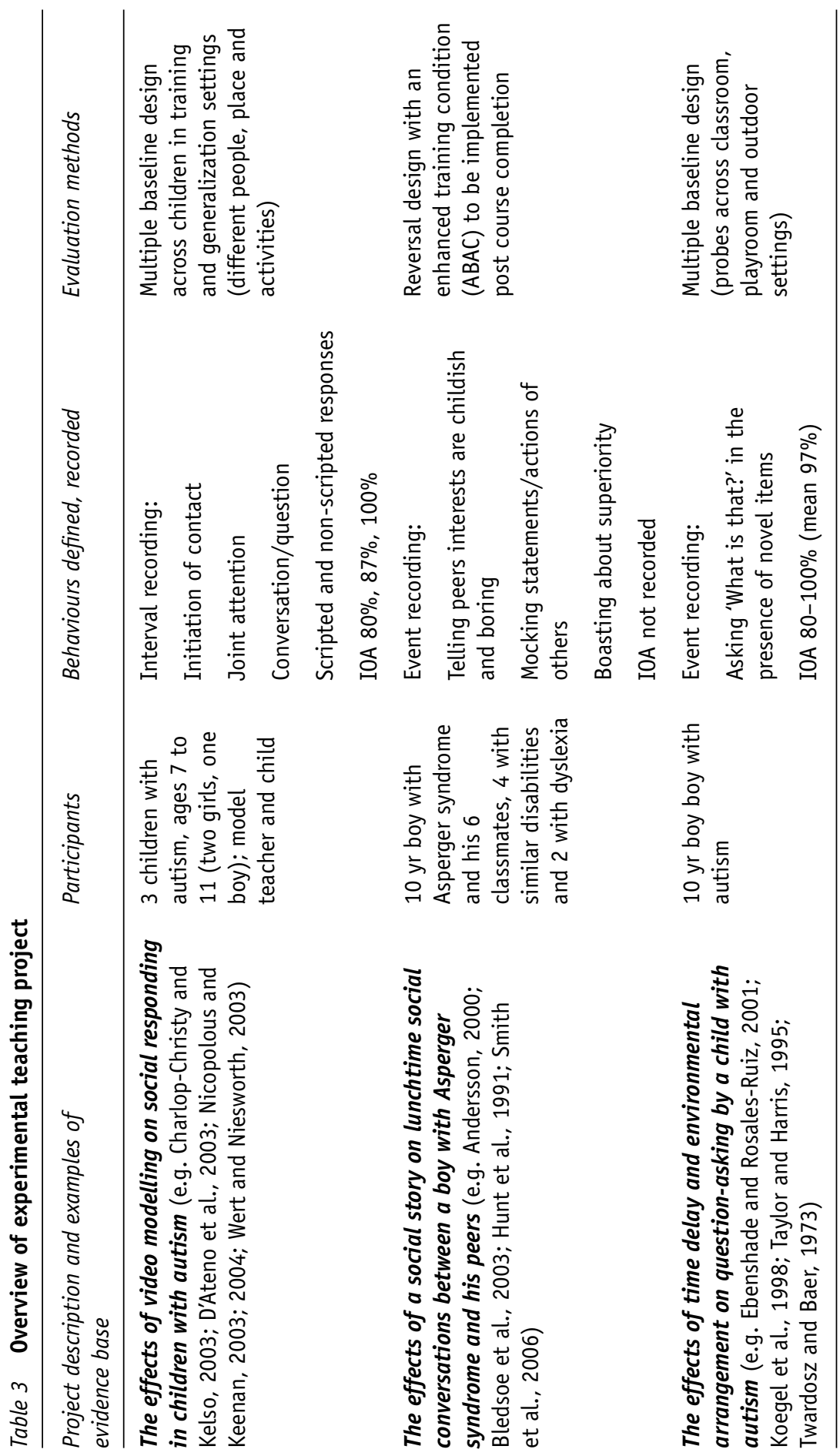




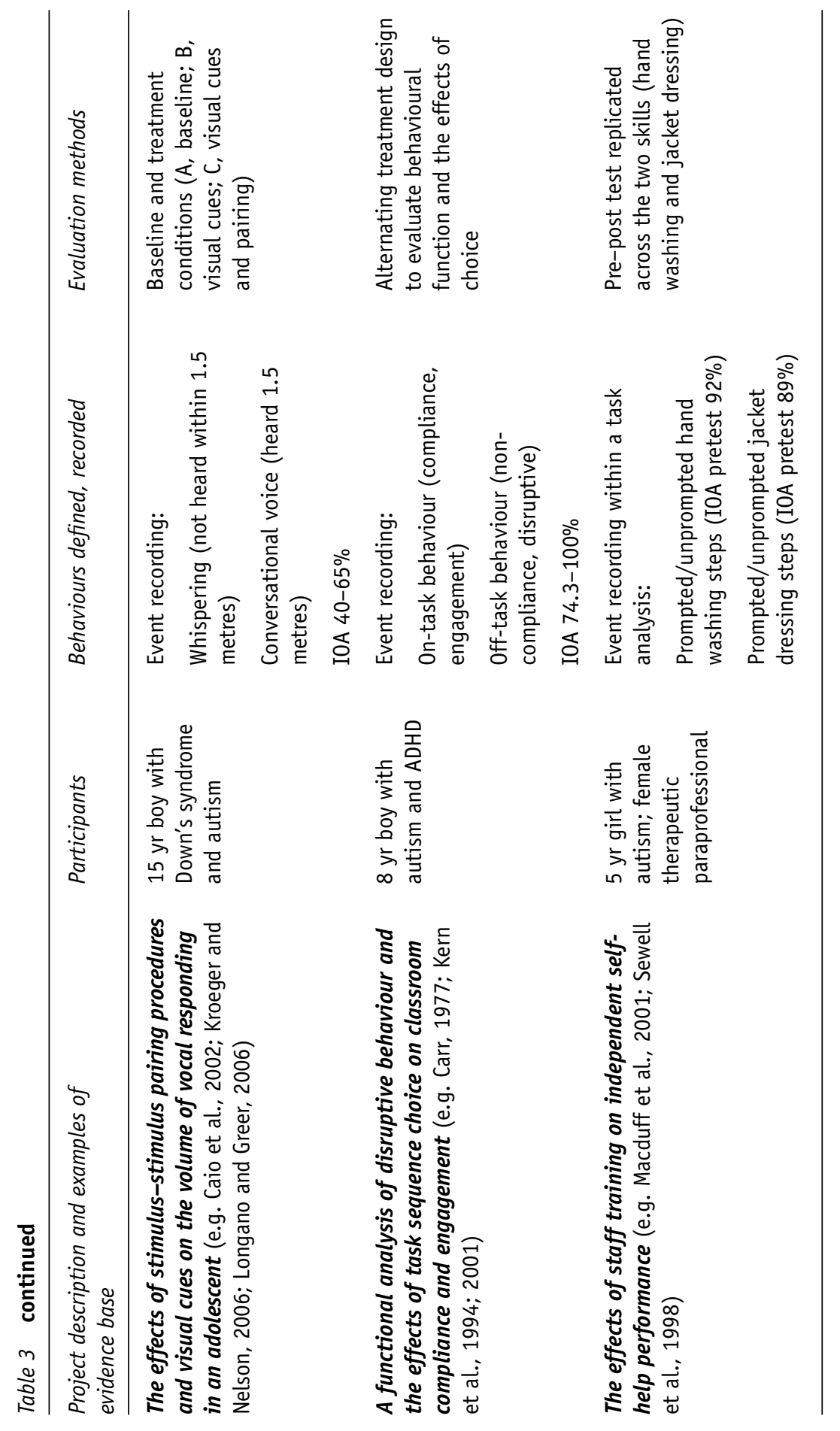


JOURNAL OF INTELLECTUAL Disabilities i 3 ( 2)

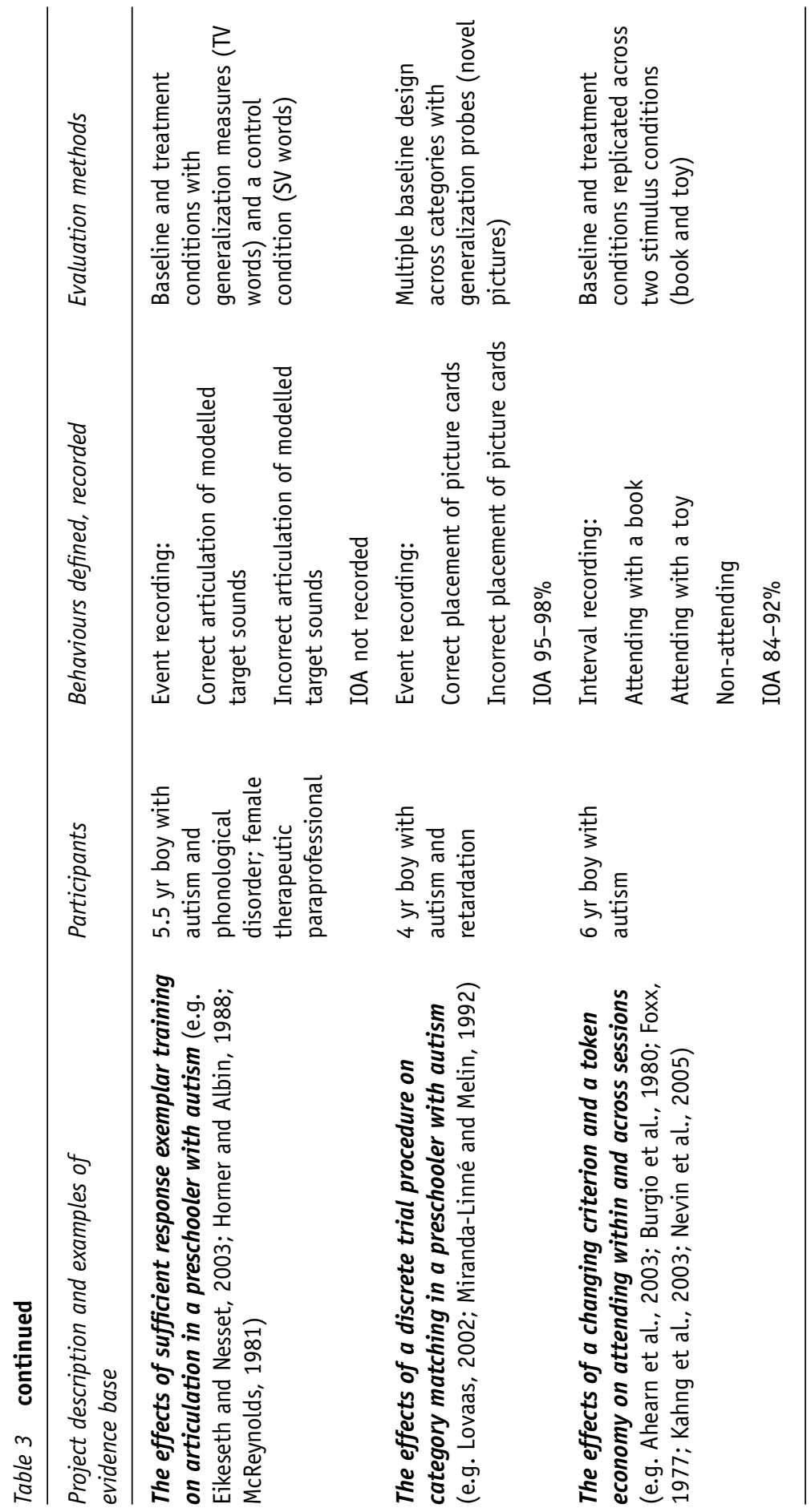




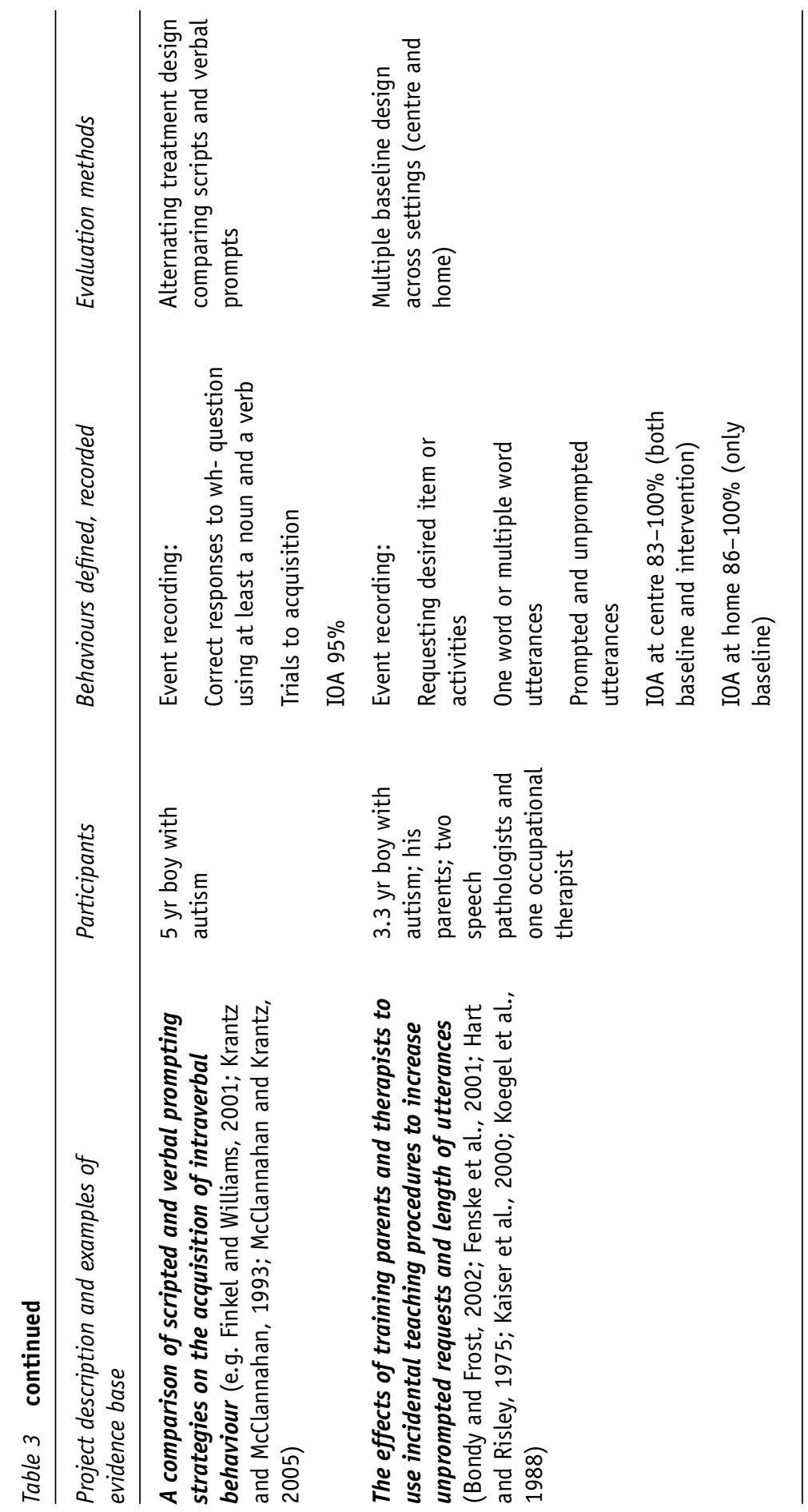


JOURNAL OF INTELLECTUAL DiSABILITIES I 3 ( 2)

Table 4 Summary of experimental teaching project results and lessons learned

Project description and

Lessons learned about evidence-based practice

result summary

The effects of video modelling on social responding in children with autism

Two of the three children demonstrated desired behaviour change in the training setting; one of those two generalized to an untrained setting

\section{The effects of a social story on lunchtime social conversations between a boy with Asperger syndrome and his peers}

Child's number of inappropriate behaviours decreased during intervention at lunchtime; anecdotally appeared to interact more with classmates; increases in challenging behaviour were observed when social story removed

\section{The effects of time delay and environmental arrangement on question-asking by a child with autism}

Question asking 'What is that?' generalized to natural situations in playroom and classroom settings; did not generalize to outdoors; child learned 20 new labels

The effects of stimulus-stimulus pairing procedures and visual cues on the volume of vocal responding in an adolescent

Student increased frequency of vocal responding in conversational and whispering voice levels
Important to attend to researcher's specification (or lack of) of assumed (or validated) conditions for success (e.g. child prerequisite skills, motivational variables, etc.)

It is useful to utilize multiple research bases (e.g. incorporation of pivotal response training components may have enhanced success of the video modelling procedures)

Limited research addressing behaviour of children with Asperger syndrome

Daily life events (e.g. illness, holidays) may have precluded consistent implementation; not clear if this occurred in published research or not

There is limited research on how to avoid stigmatizing youth in front of their peers

Progress in one skill area can lead to the need for investigating new bodies of research (e.g. selfmanagement intervention research)

Limited information in the studies on how to assess teaching stimuli (novel items) for children who learn labels quickly; also, how to continue to include meaningful stimuli while teaching the skill of question-asking

An analysis of teaching conditions was important in order to programme for generalization

Daily life events (e.g. illness, holidays) may have precluded consistent implementation; not clear if this occurred in published research or not

Initial definitions may need to be revised based on a particular child's circumstances (e.g. normal conversational tone was voice level audible at 1.5 metres but in reality this definition was less than normal conversational level and was changed) 
Table 4 continued

Project description and

result summary

\section{A functional analysis of disruptive behaviour and the effects of task sequence choice on classroom compliance and engagement}

Functional analysis results were inconclusive. Task results indicated that frequency of all behaviours (compliance, noncompliance, disruptive behaviour) and engagement in task was higher in the choice than in the no-choice intervention

\section{The effects of staff training on independent self-help performance}

At the end of the study the child could wash her hands independently as well as put on her jacket without prompts (with exception of zipping) and overall prompts decreased

\section{The effects of sufficient response exemplar training on articulation in a preschooler with autism}

After an adaptation to the response exemplar, the child learned to correctly articulate the Swedish 'tvi' sound during training sessions in all words beginning with the sound (response generalization). No training was given for the second targeted sound 'sv' and no setting generalization was assessed (although other staff reported improvement with the 'tvi' sound)
Lessons learned about evidence-based practice

Functional analysis yielded results inconsistent with descriptive assessments, suggested need for further observation, and perhaps indicated multiple functions

Additional measures not present in an evidence source may be needed to understand nature of changes (e.g. duration of responding, number of instructional learning units)

Counterbalancing intervention conditions and introducing two different treatment conditions is difficult and can produce results that seem either consistent or contrary to observations in other contexts (e.g. in other situations the child seemed more compliant and less disruptive when given a choice)

Often you begin with one set of goals or clinical concerns and then shift (e.g. began with child self-help but quickly shifted to staff training on promoting independence)

Change of intervention focus can be time consuming in terms of restarting the evidence investigation process

Changing the adult's behaviour requires a different body of evidence as well as different consultant training skills

Even when conducting a direct replication, particular details will need to be adjusted for a given child (e.g. changing the initial target word, the second target sound was acquired quickly and produced rapid generalization to other words, but only after trying another word that was motivationally, but not phonemically, more complicated)

Observing generalization of treatment effects can be time consuming and difficult and practitioners have to balance the relative importance of quantified information and available resources 
JOURNAL OF intellectual Disabilities i 3 ( 2)

Table 4 continued

Project description and

Lessons learned about evidence-based practice

result summary

The effects of a discrete trial procedure on category matching in a preschooler with autism

Child correctly categorized fruits, tame animals and clothes during training sessions. This skill was not displayed in a 3 week maintenance check

\section{The effects of a changing criterion and a token economy on attending within and across sessions}

Results indicated a slight increase in attending behaviour in one condition (toy rabbit) but not in the other condition (picture book)

\section{A comparison of scripted and verbal prompting strategies on the acquisition of intraverbal behaviour}

The child acquired intraverbal behaviour (wh- questions) following both intervention procedures. When comparing the visual scripting and verbal prompting strategies, however, it was apparent that the scripted strategy was more efficient. Maintenance checks revealed that he could respond when provided with scripted prompt
While the child may display correct responding similar to published research effects, they may not be under the same stimulus or consequence control as participants in the intervention study (e.g. a video analysis of the intervention indicated teacher cuing and possible attending to irrelevant dimensions of the stimuli)

The simplest intervention procedure may not yield the most durable outcomes

Direct use of measures from published research may or may not be critical in order to see similar effects (e.g. duration recording of attending may have been more appropriate than interval recording)

Collateral measures are important in order to assess the full effect of the intervention (personnel anecdotally noted decrease in stereotypy even though not the primary goal)

In order to replicate some procedures it is sometimes necessary to teach prerequisite skills (e.g. previous to baseline, students conducted a pre-intervention probe which revealed that the boy did not follow the instruction 'read' or 'say'; the students then had to teach the boy to discriminate between the two requests)

When comparing two procedures it can be difficult to equalize procedural implementation (e.g. authors noted that they were more systematic fading the scripted prompt than the verbal prompts) 
ROLL-PETTERSSON \& ALA'I-ROSALES: BLENDED AND GUIDED TECHNOLOGIES

Table 4 continued

Project description and

Lessons learned about evidence-based practice

result summary

\section{The effects of training parents and therapists to use incidental teaching procedures to increase unprompted requests and length of utterances}

The results showed that incidental teaching increased the number of unprompted utterances and the length of those utterances at home and at the autism centre (training centre, not his preschool placement), although the results in the home setting were higher
The procedural descriptions required in evidence-based practice aid trainers in communicating procedures to parents and practitioners

Particular aspects of previous research may turn out to be critical for successful replication (e.g. continuous reinforcer assessments and systematic reinforcement of attempts were required to maintain the child's high rate of correct responding)

Although gains will be observed, generalization may be limited if providers are not trained (e.g. it may have been better for the child, and more ecologically and socially valid, if training had occurred in the preschool in addition to the home (training in the home produced greater change than training in the autism centre)

degrees of experimental control, the students demonstrated clinically significant behaviour changes in a majority of the participating children. Each group defined behaviours and conditions of concern; identified relevant literature; selected, adapted, and applied appropriate procedures; and documented the process through reliable data collection, visual analysis, and written and oral report. The projects spanned communication, social and daily living, and academic skill domains. Eleven of the I3 children in the projects evidenced favourable behaviour changes in at least one area.

\section{Teacher responses}

Structured evaluation The eighteen students who completed the course filled in the Teacher Evaluation Instrument (modified version of Grey et al., 2005), based on $\mathrm{I} 3$ items in which responses were made on a scale of $\mathrm{I}=$ less than expected to $5=$ greater than expected. In response to all item student ratings, the mean for 12 of the items was a 4 or above; the median for five of the items was 5, and for the remaining eight was 4 . In regard to overall quality of the course, the students rated that it was much higher than expected, with mean 4.3, median 5.0; CD lectures, mean 4. I, median 4.0; quality of setup of lectures, mean 4.2 , median 4.0 ; contribution of ethical document, mean 4.2, median 4.0; contribution of the curriculum analysis, mean 4.4 , median 4.0 ; 'course content will affect my teaching and professional practice', mean 4.8 , median 5.0; contribution of teaching 
project component, mean 4.4, median 4.5; participation in telecom group supervision, mean 4.0 , median 4.0; contribution of hearing other teaching projects with feedback, mean 4.5 , median 5.0 ; 'as a result of the work in this course my future/other students will benefit', mean 4. I, median 4.0; 'the money invested in this course by myself or by my employer was justified', mean 4.4, median 5.0; 'course expanded my understanding of Applied Behaviour Analysis', mean 4.7, median 5.0; and 'this course has prepared me for taking the Board Certified Behaviour Analysis exam', mean 3.9, median 4.0 .

Open-ended evaluation Students were also asked to respond to three open-ended questions. Thirteen students responded to the first question ('most useful aspects of the course'). Their responses reflected two areas of importance: 'the scientist-practitioner approach' and 'assignments'. In the first area, students stated that they had a better understanding of the depth of $A B A$ in regard to principles and procedures and how to apply them in practical settings. One student wrote, 'How to work with observations and interventions, set clear goals, and evaluate'. Students also reported the importance of being ethical, taking data, and conducting assessments, and the role of motivation when collaborating with parents and other personnel. In the area of assignments, students discussed the benefits of opportunities to practise what they were learning (the guided-design projects), perceived the assignments as being important (specifically, the analysis and understanding of peer-reviewed experiments, creating the ethical document, conducting the curriculum review, and designing and implementing the teaching project). They also found the face-to-face (in person or telecom) meetings with the second author extremely beneficial.

Negative aspects of the course fell into two categories, 'technical' and 'structural'. With regard to technical problems, several students commented on the need for better quality CD equipment (audibility). Pertaining to the structure of the in-class meetings, a couple observed that they might have been more structured. One of the 18 students remarked that the course workload was relatively heavy, given that it was only i5 ECTS over the year, and that there were too many group assignments. Two comments concerned areas to which students wished they had had more exposure: 'more role play even if we are shy, it is important to try' and 'collecting data and deciding what to collect'.

Six students provided general comments and impressions. All responses included favourable comments, such as 'good and relevant literature'; 'inspiring course'; 'a perfect fit for us who work in the habilitation centre'; 'extremely interesting and important'; 'the course has given me the inspiration and strength to go on with $\mathrm{ABA}^{\prime}$; 'extreme competence and 
ROLL-PETTERSSON \& ALA'I-ROSALES: BLENDED AND GUIDED TECHNOLOGIES

kindness'; and 'great collaboration with Shahla and North Texas University'!!

Three major themes could be found across the students' written comments directly pertaining to one of the final class days when the instructor-at-distance came to Sweden and students discussed total course content through the case-study scenario exercises: 'perspective-taking', 'relevance of case-study integration', and 'importance of accountability and assessment'.

Perspective-taking Of the 12 comments pertinent to this theme, seven used the term 'perspective'. Two samples of statements on this theme were: 'Interesting and new knowledge through the case studies, it is very seldom that we discuss children and families from a holistic perspective'; and 'Behaviour analysis is built on thinking functionally and taking data, to have a long term perspective with consideration of short term goals ... and individualize for each person and families' needs, prerequisites, and interests'.

Relevance of case-study integration Five comments were related to total course content covered through the case-study scenario exercises. Three statements on this theme were: 'It has been interesting to work from cases and have group discussions' , Interesting and new knowledge through the case studies', and 'The way the day was organized gave me a lot of thoughts on how one interacts with parents and children, and about talking about difficult and sensitive subjects'.

Importance of accountability and assessment Five comments used the terms 'data' or 'assess' regarding what was learnt from case-study vignettes. Two examples were: 'Importance of first listening to parents and analysing what they need and their life-styles, and then documenting and assessing each step'; and 'It is important to emphasize the empirical aspect of ABA and back up what we do with data'.

\section{Discussion}

The purpose of this article was to describe the outcomes of a graduate level scientist-practitioner course in Applied Behaviour Analysis and autism intervention. The course employed guided design (to address the complexity of the subject matter to be learned) and blended-learning technologies (to address the shortage of expertise available to train students). It was designed to address the competencies required by the Behaviour Analysis Certification Board ${ }^{\mathrm{TM}}$ (Shook et al., 2004) and the Association for Behavior Analysis Autism Special Interest Group (2007). Its goal was to 
train the participating students, all of whom were multidisciplinary professionals, to incorporate research evidence into their clinical settings in order to improve their ability to impart socially significant skills in children with autism. The effectiveness of the course was assessed by examining the students' experimental teaching projects and their perceptions of the course.

Results indicated that by combining blended-technology (Bonk et al., 2004) and guided-design instructional techniques (Trivette, 2005), the students developed problem-solving skills and produced socially significant behaviour changes that reflected research-based interventions. They successfully engaged in evidence-based practice (identified important areas for behaviour change, searched the literature, evaluated and adapted experimental findings, developed evaluation methods, and applied and modified procedures) and appropriately described the processes in their experimental teaching project presentations. Regarding the goal of producing socially valid behaviour changes, a majority of the children (I I of the I3) evidenced favourable behaviour changes as indicated by the data from the experimental teaching projects. Five of the i children displayed clear gains, as demonstrated through multiple baseline or alternating treatment designs with IOA in the following areas: social responding, asking questions, correct responses to 'wh- questions', and requesting preferred activities in a natural setting. Six of the i c children demonstrated behaviour improvements in the areas of social conversation at lunch, vocal responses, compliance, independent performance, pronunciation of words, and playing with toys. However, in these six cases, it is not possible to attribute the changes with certainty to the intervention, due to lack of rigorous experimental design (indicating a functional relationship between a behaviour and an intervention), and confounding variables created by a child's absence or by modified teaching goals. Nevertheless, improvements were achieved within the experimental teaching project time frame.

In their own evaluations and reflections on the experimental teaching project, the students discussed several issues. For example, they reported obstacles in accessing and utilizing published research. Search engines did not consistently produce articles, and extensive reference cross-listing and researches were required. Often, the 'Methods' sections of published articles were not as detailed as was needed in order to replicate the intervention procedures, and some application areas were inadequately addressed in the published research (e.g. validated procedures for children with Asperger syndrome, or procedures to increase extended conversation skills).

Several students noted that it was not always appropriate to directly replicate studies, and that a skilled scientist-practitioner should be able to 
adjust interventions to meet the specific needs of individual pupils and settings (e.g. analyses of stimulus control and data systems, and choice of target behaviours and reinforcing consequences). Furthermore, when presented with a lack of research, practitioners should be able to set up an experimental analysis for a promising but untested procedure. Students learned that one of the strengths of a behavioural approach is that it is to some extent 'procedure free'. ABA as described by Baer et al. (1968) is a scientific approach to improving the human condition. Thus, any reasonable set of environmental interventions is amenable to experimental analysis within a behavioural framework. For example, in one group, the students were able to take procedures often not thought of as behavioural, such as 'social stories', and evaluate whether the procedures might be useful for a pre-teen with Asperger syndrome who would benefit from increased conversational skills with peers. Taken together, this example illustrates the importance of professionals being well informed about multiple pedagogical approaches that are conceptually consistent with behavioural principles. The main concern is that the scientist-practitioner should demonstrate that those approaches effectively meet the needs of the autistic pupil in his or her eco-cultural setting.

In terms of student 'perceived importance', and with respect to social validity, students reported the course both improved their professional practice and expanded their knowledge of Applied Behaviour Analysis. The majority of the i3 scale items had median response ratings of 4.0 or above ( $\mathrm{I}=$ lowest to $5=$ highest rating). Five items had ratings with a 5.0 median: overall quality of course; 'course content will affect my teaching and professional practice'; contribution of hearing other teaching projects with feedback; 'the money invested by myself or my employer was justified'; and 'the course expanded my understanding of Applied Behaviour Analysis'. In addition, the guided-design methodology seemed to lend itself to a holistic perspective concerning intervention, families, ethics, and accountability.

This project strengthens and extends findings by Grey et al. (2005) in several ways. First, the students learned scientist-practitioner skills that produced important behaviour changes in the children under their care. Second, the students reported that the course process was meaningful, well designed and valuable. Having instructors both on-site and at a distance, collaborating and planning the course, probably influenced the students' high social validity ratings. During the development phases of the course, the instructors had repeated discussions directed at fine-tuning the "meaningfulness' of the activities. Typically, the starting point of any given guided-design activity was different from the final project assigned to the students. Third, the course added generality to the approach by 
demonstrating that the training also applies to several other areas of skill acquisition in children with autism. In addition to decreasing challenging behaviour and increasing alternatives, the course included behaviour intervention targets specific to the social-communicative deficits that characterize autism. Finally, the results from the course suggest that guided design and blended instruction are viable, effective pedagogies when the skills to be taught are complex and require problem-solving skills, even when the needed expertise is not geographically available. Blended learning made professional expertise feasible regardless of time constraints and physical boundaries, and was an effective method for avoiding possible problems concerning the conversion of university credits from one country to another.

It should be noted however that, as with Grey et al., no controls were employed to evaluate the relative effects of this pedagogical approach. Future research may address this issue. For example, one could ask a large group of students to design an intervention and present the outcomes before any formal coursework occurred and then randomly place students in smaller groups to compare the approaches (a traditional course, a guided-instruction course, a blended course, and a guided-blended course). The outcomes of training would be evaluated by comparing the pre- and post-intervention outcomes and student perceptions in each of the four groups. While this may be possible, it is also important to note that the current effort, as well as that of Grey et al., represents an ad valorem approach (doing the best we can under the circumstances) that addresses the immediate needs of the field by tailoring a curriculum and providing the education to a small group of professionals (Shook et al., 2002). The rising incidence of autism, combined with a shortage of trained professionals, calls for prudence when developing research programmes in higher education pedagogy. But, for the sake of the populations served, the more data available that support particular pedagogies, the more assurance there is that the system is producing effective professionals. Hopefully, through increased efforts in this area, it will be possible to move from ad valorem to the 'gold standard' (evidenced-based higher education) of training in Applied Behaviour Analysis and autism (Shook et al., 2002). According to the National Research Council (200I), a national agenda for upgrading personnel preparation should also be based on statistical information that has been coordinated with relevant aspects of the infrastructure. Also, in order to sustain development, masters and doctoral courses as well as intervention research will need to be recognized, implemented, and supported (Shook et al., 2002).

The 18 students who completed and passed the course have obtained the training to apply and evaluate interventions and practices based on a 
scientific methodological approach. They will do so within the Swedish infrastructure. If each of these students employs the scientist-practitioner model in their professional careers and each provides services to 20 children with autism over a io year teaching and professional career (a conservative number given the incidence), they will contribute to improving the education and quality of life of 360 children with autism. In reality, this is a small but important step in the right direction. For change to occur in Sweden, it will be important to obtain special education statistics regarding the number of children with autism and where those children are being educated. Furthermore, for the change to be sustainable, advanced education courses such as this one will need to be offered to meet the needs of the autism population and the professionals serving those children. Research on interventions and training methods will have to be established, ongoing, and maintained.

\section{Impact summary}

The results from the study indicate that it is possible to introduce the scientist-practitioner model by combining guided-design instructional strategy with blended-learning technology. Through blended learning, the instructors strategically offered expertise, planned cultural adaptations, and transferred knowledge from the experts to students. The guided-design methods offered a format for organizing class information and performance competencies in a practical, meaningful, and challenging manner. The project focused on increasing professional competency and expertise in Sweden; its lessons, however, are applicable to other regions or nations in similar circumstances. An additional benefit derived from the course is that it has the potential to foster cross-cultural understanding and increased global collaboration. Both instructors and students gained insight into the multiple similarities and differences between their respective cultures with respect to dealing with complex, macro-systemic aspects of their societies, affecting children with autism and their families.

\section{Acknowledgements}

The authors would like to thank the City of Stockholm, The Kempe Carlgrenska Foundation and The Clas Groshinsky Memory Foundation for funding this course.

\section{References}

Ahearn, W. H., Clark, K. M., Gardenier, N. C., Chung, B. I. \& Dube, W. V. (2003)

'Persistence of Stereotypic Behavior: Examining the Effects of External Reinforcers', Journal of Applied Behavior Analysis 36 (4): 439-48. 
Ala' i-Rosales, S. A., Thorisdottir, S. \& Etzel, B. C. (2003) 'Behavioral Teacher Training Programs', in Budd \& Stokes (eds) A Small Matter of Proof: The Legacy of Donald M. Baer. Reno, NV: Context.

Allen, E. I., Seaman, J. \& Garrett, R. (2007) Blending In:The Extent and Promise of Blended Education in the United States. Needham, MA: Sloan Consortium.

Anderson, S. R. \& Romancyzk, R. G. ( 1999) 'Early Intervention for Young Children with Autism: Continuum-Based Behavioral Models', Journal of the Association for Severe Handicaps 24 (3): $162-73$.

Andersson, B. (2000) 'Bygga upp ett erfarenhetsbibliotek genom sociala berättelser och seriesamtal: ett pedagogiskt arbetssätt för barn/elever/personer med neuropsykiatriska problem som autism, Aspergers syndrom, Tourettes syndrom, DAMP, AD/HD' ('Building an Experience Based Library through Social Stories and Series Discussions: An Educational Approach for Children/Pupils/Persons with Neuropsychiatric Problems such as Autism, Asperger Syndrome, Tourette Syndrome, DAMP, AD/HD’). Ängelholm Specialpedagog Birgitta Andersson AB.

Association for Behavior Analysis Autism Special Interest Group (2007) 'Consumer Guidelines for Identifying, Selecting and Evaluating Behavior Analysts Working with Individuals with Autism Spectrum Disorders'. www.abainternational.org/ Special_Interests/AutGuidelines.pdf.

Baer, D. M., Wolf, M. M. \& Risley, T. R. ( 1968) 'Some Current Dimensions of Applied Behavior Analysis', Journal of Applied Behavior Analysis I : 9I-7.

Baker, D. B. \& Benjamin, L. T. (2000) 'The Affirmation of the Scientist-Practitioner: A Look Back at Boulder', American Psychologist 55 (2): 24I-7.

Bernstein, G. S. ( 1982) 'Training Behavior Change Agents: A Conceptual Review’, Behavior Therapy I3 (I): I-23.

Bibby, P., Eikeseth, S., Martin, N. T., Mudford, O. C. \& Reeves, D. (200 I) 'Progress and Outcomes for Children with Autism Receiving Parent-Managed Intensive Interventions', Research in Developmental Disabilities 22 (6) : 425-47.

Bledsoe, R., Smith, B. M. \& Simpson, R. (2003) 'Use of a Social Story Intervention to Improve Mealtime Skills of an Adolescent with Asperger Syndrome', Autism 7 (3): 289-95.

Bohlin, G., Bromark, G., Granat, T., Haglund, N., Sjöholm-Lif, E. \& Zander, E. (2004) Mångsidiga intensiva insatser för barn med autism i förskoleåldern: En rapport inom projektet evidensbaserad habilitering (Comprehensive Intensive Interventions for Preschool Children with Autism: A Report within the Project Evidence-Based Habilitation). Föreningen Sveriges Habiliteringschefer/ Handikapp och Habilitering (The Swedish Association for Habilitation Employers): Stockholm läns landsting.

Bondy, A. \& Frost, L. (2002) The Picture Exchange Communication System Training Manual. Newark, DE: Pyramid.

Bonk, C. J., Kim, K.-J. \& Zeng, T. (2004) Handbook of Blended Learning: Global Perspectives, Local Designs: San Francisco: Pfeiffer.

Burgio, L. D., Whitman, T. L. \& Johnson, M. R. ( 1980) 'A Self-Instructional Package for Increasing Attending Behavior in Educable Mentally Retarded Children', Journal of Applied Behavior Analysis iz (3): 443-59.

Caio, F. M., Carr, J. E. \& Michael, J. (2002) 'The Effects of a Stimulus-Stimulus Pairing Procedure on the Vocal Behavior of Children Diagnosed with Autism', The Analysis of Verbal Behavior I8: 3-I3.

Carr, E. G. (1977) 'The Motivation of Self-Injurious Behavior: A Review of Some Hypotheses', Psychological Bulletin 84 (4): 800-I6. 
Centers for Disease Control (2007) 'Prevalence of the Autism Spectrum Disorders in Multiple Areas of the United States, Surveillance Years 2000 and 2002'. Department of Health and Human Services. http://www.cdc.gov/ncbddd/dd/ addmprevalence.htm (24 January 2008).

Charlop-Christy, M. H. \& Kelso, S. E. (2003) 'Teaching Children with Autism Conversational Speech Using a Cue Card/Written Script Program’, Education and Treatment of Children 26 (2): 108-27.

D’Ateno, P., Mangiapanello, K. \& Taylor, B. A. (2003) ‘Using Video Modeling to Teach Complex Play Sequences to a Preschooler with Autism', Journal of Positive Behavior Interventions 5:5-II .

Demchak, M. (1987) 'A Review of Behavioral Staff Training in Special Education Settings', Education and Training in Mental Retardation 22: 205-17.

Dunst, C.J., Trivette, C.M. \& Cutspek, P.A. (2002) 'Toward an Operational Definition of Evidence Based Practices', Centerscope I: I- IO.

Ebenshade, P. H. \& Rosales-Ruiz, J. (200I) 'Programming Common Stimuli to Promote Generalized Question-Asking', Journal of Positive Behavior Interventions 4: 199-2 IO.

Eikeseth, S. \& Nesset, R. (2003) 'Behavioral Treatment of Children with Phonological Disorder: The Efficacy of Vocal Imitation and Sufficient-Response-Exemplar Training', Journal of Applied Behavior Analysis 36 (3): 325-37.

Fenske, E. C., Zalenski, S., Krantz, P. J. \& McClannahan, L. E. (1985) 'Age at Intervention and Treatment Outcomes for Autistic Children in a Comprehensive Intervention Program', Analysis and Intervention in Developmental Disabilities 5: 49-58.

Fenske, E. C., Krantz, P. \& McClannanhan, L. E. (200I ) 'Incidental Teaching: A NotDiscrete-Trial Teaching Procedure’, in Catherine Maurice, Gina Green \& Richard M. Foxx (eds) Making a Difference: Behavioral Intervention for Autism, pp. 75-82. Austin, TX: Pro-Ed.

Finkel, A. S. \& Williams, R. L.(200I ) 'A Comparison of Textual and Echoic Prompts on the Acquisition of Intraverbal Behavior in a Six-Year-Old Boy with Autism', Analysis of Verbal Behavior I8: 6I-70.

Folkö, M. (2005) 'D-uppsats. Föräldrars uppfattning om givna interventioner till små barn med autism: Hur passar åtgärderna in i familjens vardag? ('Parents' Perceptions of Specific Interventions for Young Children with Autism: How Do Interventions Fit Family Routines?', doctoral thesis). Västerås: Mälardalens Högskola.

Foxx, R. M. (1977) 'Attention Training: The Use of Overcorrection Avoidance to Increase the Eye Contact of Autistic and Retarded Children', Journal of Applied Behavior Analysis Io (3): 489-99.

Gambrill, E. (1999) 'Evidence-Based Clinical Behavior Analysis, Evidence-Based Medicine and the Cochrane Collaboration', Journal of Behavior Therapy and Experimental Psychiatry 30 (I): I-I4.

Geddes, J. R. \& Harrison, P. J. ( 1997) 'Closing the Gap between Research and Practice', British Journal of Psychiatry I7I: 220-25.

Goldiamond, I., Dyrud, J. E. \& Miller, T. (1965) 'Practice as Research in Professional Psychology', The Canadian Psychologist 6: i Io-28.

Goldstein, H. (2002) 'Communication Interventions for Children with Autism: A Review of Treatment Efficacy’, Journal of Autism and Developmental Disorders 32: 373-96.

Grey, I. M., Honan, R., McClean, M. \& Daly, M. (2005) 'Evaluating the Effectiveness of Teacher Training in Applied Behaviour Analysis', Journal of Intellectual Disabilities 9 (3): 209-27.

Harchik, A. E., Sherman, J. A., Sheldon, J. B. \& Strouse, M. C. (1992) 'Ongoing 
Consultation as a Method of Improving Performance of Staff Members in a Group Home', Journal of Applied Behavior Analysis 25: 599-6ro.

Hart, B. \& Risley, T. R. ( 1975) 'Incidental Teaching of Language in the Preschool', Journal of Applied Behavior Analysis 8 (4): I I-20.

Horn, R. A., McGowan, M. R., Mitchell, D. R., Mellott, R. A., Lilly, K. \& Martinez, L. (2007) 'A Pilot Study Examining the Longer Term Stability of the Scientist Practitioner Model of Training', American Behavioral Scientist 50: 830-4I .

Horner, R. H. \& Albin, R. W. (1988) 'Research on General-Case Procedures for Learners with Severe Disabilities', Education and Treatment of Children I I (4): 375-88.

Horner, R. H., Carr, E. G., Hallé, J., McGee, G., Odom, N. \& Wolery, M. (2005) 'The Use of Single-Subject Research to Identify Evidence-Based Practice in Special Education', Exceptional Children 7r: 165-79.

Howard, J. S., Sparkman, C. R., Cohen, H. G., Green, G. \& Stanislaw, H. (2005) 'A Comparison of Intensive Behavior Analytic and Eclectic Treatments for Young Children with Autism', Research in Developmental Disabilities 26: 359-83.

Hunt, P., Alwell, M. \& Goetz, L. (199I) 'Interacting with Peers through Conversation Turn Taking with a Communication Book Adaptation', Augmentative and Alternative Communication i7 (2): 117-26.

Johnson, C. P. \& Myers, S. M. (2007) 'Identification and Evaluation of Children with Autism Spectrum Disorders', American Academy of Pediatrics 120: 1182-215.

Kahng, S. W., Boscoe, J. H. \& Byrne, S. (2003) 'The Use of Escape Contingency and a Token Economy to Increase Food Acceptance', Journal of Applied Behavior Analysis 36 (3): 349-53.

Kaiser, A. P., Hancock, T. B. \& Nietfeld, J. P. (2000) ‘The Effects of Parent-Implemented Enhanced Milieu Teaching on the Social Communication of Children Who Have Autism', Early Education and Development I I (4): 423-46.

Kern, L., Dunlap, G., Childs, K. E. \& Clarke, S. (1994) 'Use of a Classwide SelfManagement Program to Improve the Behavior of Students with Emotional and Behavioral Disorders', Education \& Treatment of Children I7 (4): 445-58.

Kern, L., Mantegna, M. E., Vorndran, C. M., Bailin, D. \& Hilt, A. (200 I) 'Choice of Task Sequence to Reduce Problem Behaviors', Journal of Positive Behavior Interventions 3 (I): 3-IO.

Koegel, L. K., Camarata, S. M., Valdez-Menchaca, M. \& Koegel, R. L. ( 1998) 'Setting Generalization of Question-Asking by Children with Autism', American Journal on Mental Retardation IO2 (4): 346-57.

Koegel, L. K., Koegel, R. L., Harrower, J. K. \& Carter, C. M. ( 1999) 'Pivotal Response Intervention I: Overview of Approach’, Journal of the Association for Persons with Severe Handicaps 24 (3): 174-85.

Krantz, P. J. \& McClannahan, L. E. (1993) 'Teaching Children with Autism to Initiate to Peers: Effect of a Script-Fading Procedure', Journal of Applied Behavior Analysis 26: I 2 I-32.

Kroeger, K. A. \& Nelson, W. M. (2006) 'A Language Program to Increase the Verbal Production of a Child Dually Diagnosed with Down Syndrome and Autism', Journal of Intellectual Disability Research 50 (2): IO I-8.

Longano, J. M. \& Greer, D. (2006) 'The Effects of Stimulus-Stimulus Pairing Procedure on the Vocal Behavior of Children Diagnosed with Autism', Journal of Early and Intensive Behavioral Intervention 3 ( I ): 62-79.

Lovaas, I. O. ( 1987) 'Behavioral Treatment and Normal Educational and Intellectual Functioning in Young Autistic Children’, Journal of Consulting and Clinical Psychology 55 ( I) : 3-9. 
Lovaas, I. O. (2002) Teaching Individuals with Developmental Delays: Basic Intervention Techniques. Austin, TX: Pro-Ed.

Lutzker, J. R. \& Campbell, R. (1994) Ecobehavioral Family Interventions in Developmental Disabilities. Belmont, CA: Thomson Brooks/Cole.

Macduff, G. S., Krantz, P. J. \& McClannahan, L. E. (200I) 'Prompts and Prompt-Fading Strategies for People with Autism', in Catherine Maurice, Gina Green \& Richard M. Foxx (eds) Making a Difference: Behavioral Intervention for Autism, pp. 37-50. Austin, TX: Pro-Ed.

Machalicek, W., O’Reilly, M., Beretvas, N., Sigafoos, J. \& Lancioni, G. E. (2007) ‘A Review of Interventions to Reduce Challenging Behavior in School Settings for Students with Autism Spectrum Disorders', Research in Autism Spectrum Disorders I : $229-46$.

McClannahan, L. E. \& Krantz, P. J. (2005) Teaching Conversation to Children with Autism: Scripts and Script Fading. Bethesda, MD: Woodbine House.

McConnell, S. (2002) 'Interventions to Facilitate Social Interaction for Young Children with Autism: Review of Available Research and Recommendations for Educational Intervention and Future Research', Journal of Autism and Developmental Disorders 32: $35 \mathrm{I}-72$.

McGee, G. \& Morrier, M. (2005) 'Personnel Preparation', in F. R. Volkmar, P. Rhea, A. Klin \& D. Cohen (eds) Handbook of Autism and Pervasive Developmental Disorders.Vol. 2: Assessment, Interventions, and Policy, zrd edn. Hoboken, NJ: Wiley.

McReynolds, L. V. ( 1981) 'Generalization in Articulation Training', Analysis and Intervention in Developmental Disabilities I $(3-4): 245-58$.

Miranda-Linné, F. \& Melin, L. (1992) ‘Acquisition, Generalization, and Spontaneous Use of Color Adjectives: A Comparison of Incidental Teaching and Traditional Discrete-Trial Procedures for Children with Autism', Research in Developmental Disabilities I3 (3): I9I-2 I0.

Myers, S. M. \& Johnson, C. P. (2007) 'Management of Children with Autism Spectrum Disorders', American Academy of Pediatrics I20: I 162-82.

National Research Council (200I) Educating Children with Autism. Washington, DC: National Academy Press.

Nevin, J. A., Davison, M. \& Shahan, T. A. (2005) 'A Theory of Attending and Reinforcement in Conditional Discriminations', Journal of the Experimental Analysis of Behavior 84 (2): 28I-303.

Nikopoulos, C. K. \& Keenan, M. (2003) 'Promoting Social Initiation in Children with Autism Using Video Modeling', Behavioral Interventions I8 (2): 87-ı०8.

Nikopoulos, C. K. \& Keenan, M. (2004) 'Effects of Video Modeling on Social Initiations by Children with Autism', Journal of Applied Behavior Analysis 37: 93-6.

Ozonoff, S., Goodlin-Jones, B. L. \& Solomon, M. (2005) 'Evidence-Based Assessment of Autism Spectrum Disorders in Children and Adolescents', Journal of Clinical Child and Adolescent Psychology 34 (3): 523-40.

Peck, C. A., Killen, C. C. \& Baumgart, D. (1989) 'Increasing Implementation of Special Education Instruction in Mainstream Preschools: Direct and Generalized Effects of Nondirective Consultations', Journal of Applied Behavior Analysis 22: 197-2 Io.

Sackett, D. L., Rosenberg, W. M. C., Gray, J. A. M., Haynes, R. B. \& Richardson, W. S. ( I996) 'Evidence Based Medicine: What It Is and Isn't. It's about Integrating Individual Clinical Expertise and the Best External Evidence', British Journal of Medicine I2: 7I-2.

Scheuermann, B., Webber, J., Boutot, E. \& Goodwin, M. (2003) 'Problems with 
Personnel Preparation in Autism Spectrum Disorders', Focus on Autism and other Developmental Disabilities I8 (3): 197-206.

Sewell, T. J., Collins, B. C., Hemmeter, M.-L, Schuster, J. W. ( 1998) 'Using Simultaneous Prompting within an Activity-Based Format to Teach Dressing Skills to Preschoolers with Developmental Delay', Journal of Early Intervention 2I (2): 32-45.

Shook, G. L., Johnson, J. M. \& Mellichamp, F. (2004) 'Determining Essential Content for Applied Behavior Analyst Practitioners', The Behavior Analyst 27 ( I ) : 67-94.

Shook, J., Ala'i-Rosales, S. \& Glenn, S. (2002) 'Training and Certifying Behavior Analysts to Work with Children with Autism', Behavior Modification 2: 253-8.

Smith, G. J., McDougall, D. \& Edelen-Smith, P. J. (2006) 'Behavioral Cusps: A PersonCentered Concept for Establishing Pivotal Individual, Family, and Community Behaviors and Repertoires', Focus on Autism and Other Developmental Disabilities 2 I : 223-9.

Stahmer, A., Ingersoll, B. \& Carter, C. (2003) 'Behavioral Approaches to Promoting Play', Autism 7 (4): 40I-I3.

Striker, G. (2000) The Scientist-Practitioner Model: Gandhi Was Right Again', American Psychologist 55 (2): 253-4.

Taylor, B. A. \& Harris, S. L. ( 1995 ) 'Teaching Children with Autism to Seek Information: Acquisition of Novel Information and Generalization of Responding', Journal of Applied Behavior Analysis 28 ( I ): 3-I4.

Trivette, C. (2005) 'Effectiveness of Guided Design Learning Strategy on the Acquisition of Adult Problem-Solving Skills', Bridges Practice-Based Research Synthesis: Research and Training Center on Early Childhood Development 3 ( I ): I-I8.

Twardosz, S., \& Baer, D. M. ( 1973) 'Training Two Severely Retarded Adolescents To Ask Questions’, Journal of Applied Behavior Analysis 6: 655-6I .

Volkmar, F. R., Paul, R., Klin, A. \& Cohen, D. (2005) Handbook of Autism and Pervasive Developmental Disorders.Vol. I: Diagnosis, Development, Neurobiology, and Behavior, zrd edn. Hoboken, NJ: Wiley.

Wert, B. Y. \& Niesworth, J.T. (2003) 'Effects of Video Self-Modeling on Spontaneous Requesting in Children with Autism', Journal of Positive Behavior Interventions 5 ( I ): 30-4.

Wolf, M. M., Risley, T. R. \& Mees, M. ( 1964) 'Application of Operant Conditioning Procedures to Behavior Problems of an Autistic Child’, Behavior Research and Therapy I : 305-12.

Correspondence should be addressed to:

Lise ROll-Pettersson PhD BCBA-D, Stockholm University, Department of Special Education, Rålambsvägen 34b, i 259 Stockholm, Sweden.

e-mail: Lise.Roll-Pettersson@specped.su.se

Shahla Ala' I-ROSAles PhD BCBA-D, University of North Texas, Department of Behavior Analysis, PO Box 310919, Denton, TX 76203, USA.

e-mail: Shahla.Alai-Rosales@unt.edu

\section{Date accepted 22/05/09}

